\title{
The Role of Effective Communication in Resolving Conflict: The Case of Kebri Dehar Town Municipality, Korhay Zone, Somali Regzional Satate, Ethiopia
}

\author{
WorkneshWoldemichael \\ MA in Social Anthropology, Social science Common Course Co-ordinator at Kebri Dehar University
}

\begin{abstract}
Effective communication is a crucial element in our lives and it is the base for the organizational objective achievement. Moreover, as it is known quality of communication has a direct impact on the quality of relationship. This is why effective communication is crucial. The general objective of this study is to assess the role of effective communication in conflict resolution process in Kebri Dehar municipality. Both primary and secondary data were obtained and used from top manager and non-managerial employees of municipality by interview and questionnaire methods of data collection. The secondary data was collected by reviewing records, journals and brochures of the municipality. The researcher has used the stratified sampling technique that is a good way to give equal chance for all departmental employees who had different responses. To analyze the findings of the study and the collected data qualitative analysis method was used. Based on the findings of the study, work over load, communication gap to resolve conflict, less attention given by management for discussion, less response of management for employees' grievances, less contribution of communication on conflict resolution process, and difference in attitude towards communication were the major problems that affect communication not to achieve its goal (conflict resolution). Finally, the student researcher recommended that management should understand the source of conflict, stimulate functional conflict, and prevent dysfunctional conflict, giving attention for discussion by management, sufficient response of management for employees' grievance, using effective communication to resolve conflict and encouraging employees' positive attitude of communication to resolve conflict can be solutions to resolve the above-mentioned problems.
\end{abstract}

Keywords:Effective communication, Conflictmanagement, information, messages, opportunity, ability, motivation

DOI: $10.7176 / \mathrm{NMMC} / 96-02$

Publication date:May $31^{\text {st }} 2021$

\section{INTRODUCTION}

\subsection{BACKGROUND}

Communication is the process of sharing ideas, information and messages with others. The most basic communication methods that are known to man are speech and non-verbal expressions such as facial expressions and body language. Apart from these basic methods of communication, there are other methods of communication. These methods began to involve and become complex (I.vonGlion, mary Ann young and Steven L.Mc Shane; 1976:392). Effective/ Good communication usually requires a two-way flow of information rather than simply delivering messages work on creating a flow of message and feedback. A Sender conveys a message, and receiver responds with feedback and perhaps a new message (Cullinan; 1996:327)

Poor or inaccurate communication can lead to conflict and negativity in the work place. It could even lead to the cancellation of deal or the loss of good will. However, in this competitive environment business cannot afford such losses (Cullinan; 1996:329). Conflict is a process in which one party perceives that its interests are being opposed or negatively affected by another party. This may be a mild disagreement between two people regarding the Best choice in decision (Mary Ann and Steven L.MC Shane ; 1976:402). On the other hand, conflict is a disagreement of ideas between and among peoples. Conflict has both destructive and constructive sides. Destructive conflict could be solved as it occurs, others wise it is a challenge to the growth of any organization. Constrictive conflict could increase innovation and creativity. Communication in modern history has many important activities. Among these, it has a great role in resolving destructive conflict and increasing constructive conflict.

Conflict often occurs due to the lack of opportunity, ability, or motivation to communicate effectively. As communication is essential to the communities of a given organization, especially for managers to coordinate the human and other resources of an organization, they required ability to communicate effectively. To coordinate these human resources they should avoid conflicts that occur between employees. To avoid these problems communication is vital (Mary Ann and Steven L. mc Shane; 1976: 408). Considering the point about the effective communication, conflict and their relation, the researcher tried to see the roles of effective communication on conflict resolution process at Solai regional state, Kebri Dehar municipality. 


\subsection{STATEMENT OF PROBLEM}

As long as people in organization work together, conflict is inevitable or unavoidable. This means as people work together the incompatibility of goals, attitudes, emotions or behaviors lead to disagreement or opposition between them. Conflicts occur because people do not agree on goals, issues, perceptions and people inevitably compete for the scare resources (Many Cullinan; 1996: 407).

Same authors say that any organization has no meaning with out communication. To reduce or if possible to avoid the above inevitable conditions, communication have a vital role. Communication is not only used for conflict resolution but also it is the basis for the organizations objectives achievements:- increasing productivity, job satisfaction, getting information about competitors dimension, to cope with modern information technology and any activates in any field of study. Thus, the fact is that communication is the crucial element in our lives. The factors that motivated the researcher to study the problem on communication of municipality were poor and not sufficient service that the employees of the municipality provide for their customers who takes service from them. Moreover, from compliant of other customers, the researcher think that poor insufficient service delivery may be from lack of communication on resolving conflict. Before this study, as the manager of municipality told to the researcher, there is no study under taken on effective communication in resolving conflict, which is a burning issue to be discussed and can be solved by the management of the organization.

Hence, the study tried to answers the following research questions:-

* What are the major factors that cause for employees conflict in Kebri Dehar municipality?

* What place does communication have in Kebri Dehar municipality?

* What are the major factors that affect communication to resolve conflict in Kebri Dehar municipality?

* What are the contributions of effective communication in resolving conflict in Kebri Dehar municipality?

* How should the municipality do to resolve conflict in the municipality by using effctive communication?

\subsection{OBJECTIVE OF THE STUDY}

\subsubsection{GENERAL OBJECTIVE}

* The general objective of this study is to asses the role of effective communication on conflict resolution process in Kebri Dehar municipality.

\subsubsection{SPECIFIC OBJECTIVES}

Specifically the study tried to achieve the following objectives:

* To asses the major factors that causes conflict in Kebri Dehar municipality

* To examine the place that communication has in Kebri Dehar municipality.

* To find out the major constraints that put on communication not to achieve the desired goal in Kebri Dehar municipality.

* To explain the contribution of effective communication in resolving conflict in Kebri Dehar municipality.

* To suggest some reasonable and relevant recommendation concerning the municipality use of communicate in resolving conflict in Kebri Dehar municipality.

\subsection{SIGNIFICANCE OF THE STUDY}

In the current world, every organization faces different controllable and uncontrollable challenges, whether it is profit making or non-profit making. In order to adapt and cope up with uncontrollable situations, organizations, mangers, and all employees of the organization together should set productive measures and at least attempt to minimize the effect of these situations on business activities. According to Stephen P.Robbins(1996,p.419) An organization is accounted for planning, coordinating, controlling and doing things in manageable course of actions to achieve its goal effectively and efficiently.

Therefore any organization whether small or large, profit or non-profit organization, needs the assessment of its business feature, nature, role, strength and weakness and functions. Considering the above importance of conducting studies, investigating the role of communication on resolving conflict is important as it is one of business element is believed to be the crucial issue for the municipality.

The beneficial bodies used by this study are-

The organizations:- After conducting this research the organization will be beneficiary in that the manager see the identified problems and recommended solutions of the study and take corrective action in the way and function of entire communication as to resolve conflict.

The researcher: - The researcher is beneficiary on getting knowledge about the study and experience on conducting such assessment and get satisfaction and other researchers can take this study as reference for conducting other similar assessment.

Other similar organizations: the study can be used for other organizations which are similar by taking this study and they can check them selves with identified problem and if the problem are originate on them they can 
take their corrective measure.

\subsection{LIMITATIONS OF THE STUDY}

There are some limitations that the researcher faced the challenges while conducting this study. These limitations are stated as follows:-

* Lack of sufficient finance for conducting the study

- Reluctance of respondents to give infotrmation and not ready to return back the questionnaire.

- Lack of consistency of respondents.

* Lack of communication because of barriers due to language problem

\subsection{SCOPE OF THE STUDY}

Even if communication has many role in different situations, in different organizations, the researcher focused only on the role of communication in resolving conflict. Because as it is known distructive conflict is challenge for the over all organization, the researcher like to study how this distructive conflict can get the solution and the researcher select effective communication from other extraneous variables such as reward, performance a appraisal which are the ways of deducting if possible eliminating conflict with in the organization.The reason for communication is selected from other extraneous variables is that communication generalize them or those extraneous variables cannot come up with out communication. On the other hand the researcher conducted the research only on the employees of Kebri Dehar municipality at Somali regional state.

\section{METHODOLOGY}

\subsection{SOURCE AND TYPE OF DATA}

Both primary and secondary data were used for this study. Hence, necessary data has been gathered from the primary sources such as non-managerial workers and top managers of kebri Dehar municipality and diferent documents such as reports, broacher, public comments, records..etc of the municipality as a source for secondary data.

\subsection{METHODS OF DATA COLLECTION}

In this study, both primary and secondary data collection methods were used. Principally, self-administrated questionnaires were proposed tool for primary data collection method. Because the time given to conduct this study is short, the researcher used this technique to get more data with in a short period. As an additional source of primary data unstructured interview was held with the top manager of Kebri Dehar municipality. And secondary data was collected through review of the company's documents as mentioned above.

\subsection{SAMPLING SIZE}

In order to come across manageable size of population the researcher selected 50 employees at the sample size of $30 \%$ from total population of 166 employees in Kebri Dehar municipality. Additionally, the researcher also included one subject, who is the top manager from the top officials of the organization for interview purpose.

\subsection{SAMPLING TECHNIQUE}

For the accessible primary data source, two types of sampling technique were employed. These are stratified sampling technique and purposeful sampling technique. Stratified sampling technique was use to gather data from the employees working in the municipality and purposeful sampling technique was used to gather information from the top manager of the municipality.The stratified sampling technique was used for the reason that the student researcher wanted to give equal chance for all departments of employees who had different responses. and the purpose full sampling technique was used to select the manager who can give more relevant and general information about municipality overview and role of communication in conflict resolution process in Kebri Dehar municipality.

\subsection{DATA PROCESSING AND ANALYSIS}

After the data is being collecting, data were processed on the activity, which involves editing, coding, and classifying data to make it suitable for further analysis. Descriptive analysis was employed to examine the findings of the study. Since it refers to procedures for organizing, summarizing, and describing quantitative data about the samples of the study.

\section{RESULT AND DISCUSSION}

\subsection{Introduction}

After the data were processed and analyzed well, it were presented by using tables, charts, and graphs with their figures and interpreted in a convenient manner accordingly. As it was explained in the methodology section, the 
information mentioned here was gathered by distributing 50 questionnaires to the employees of Kebri Dehar municipality. Among these questionnaire two were not returned and three did not provide inconsistence information and the remaining 45 were used for analysis and interpretation of data here after.

The analysis and justifications of the findings from the information were approached by summarizing the relevant question and respective responses for a topic on an issue and then further analyzed sequentially. In addition to questionnaire the interview responses from the administrative body of the municipality were also analyzed.Pie chart, graph, and tables were used to present interpreted data by using descriptive analysis method.

\subsection{Personal Information of the respondents}

The personal information includes data about sex, age, educational status, and working experience of the respondents that was used to appropriately know the respondents' characteristics and background information before going to the basic parts of the study.

Figure 1: Sex distribution of respondents

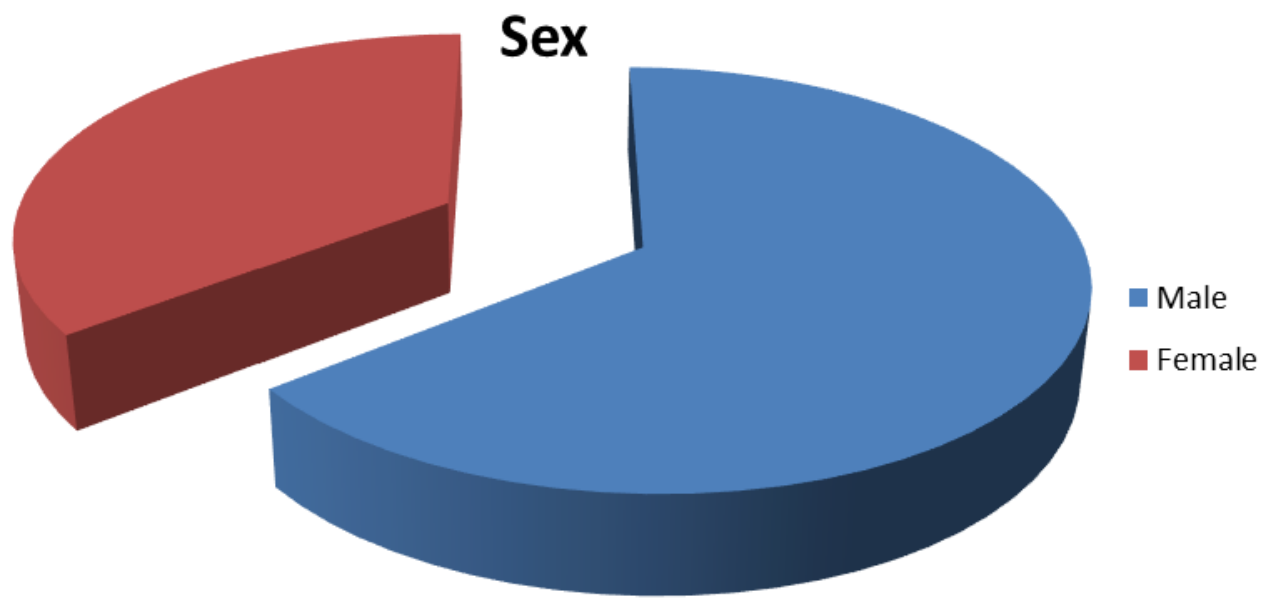

Source: Own Survey 2021,

As indicated on the above figure, among the total 45 respondents, $29(64.4 \%)$ were male and the remaining $16(35.6 \%)$ were female. This shows that the participation of female was less than males in over all activities of organization and in communication process.

\section{Figure 2: Age Distribution of respondents}

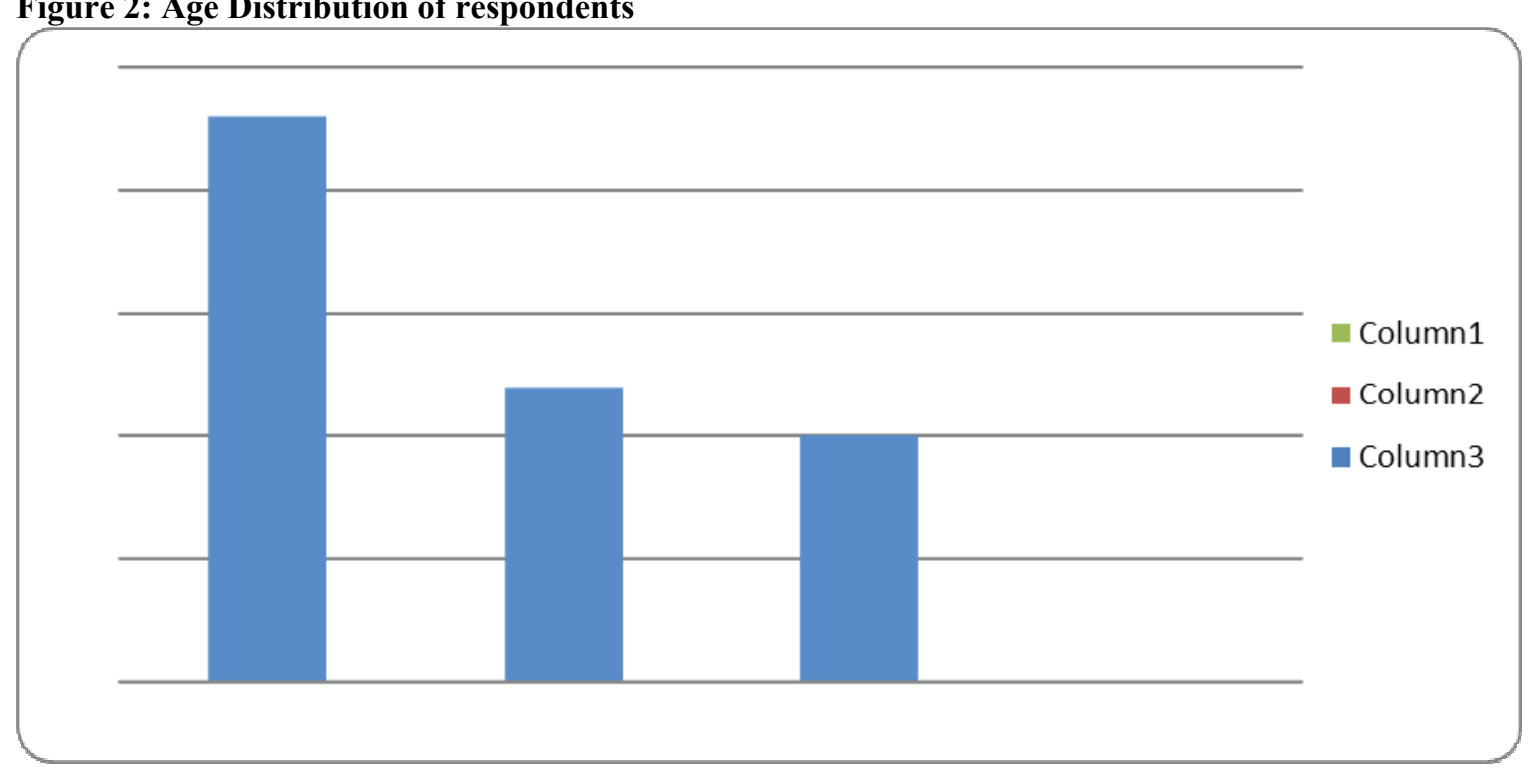

Source: Own Survey 2021,

According to the above figure the range age out of the total respondents, 23(51.1\%) of them were between 18-30 years age, $12(26.67 \%)$ of them were 30-40 years age and the remaining $10(22.22 \%)$ of respondents were between 40-50 age group. As we observed from the finding, the largest proportion of the study population lied 
between age group of 18-40.

Figure 3: Information regarding educational status and work Experience of respondents.

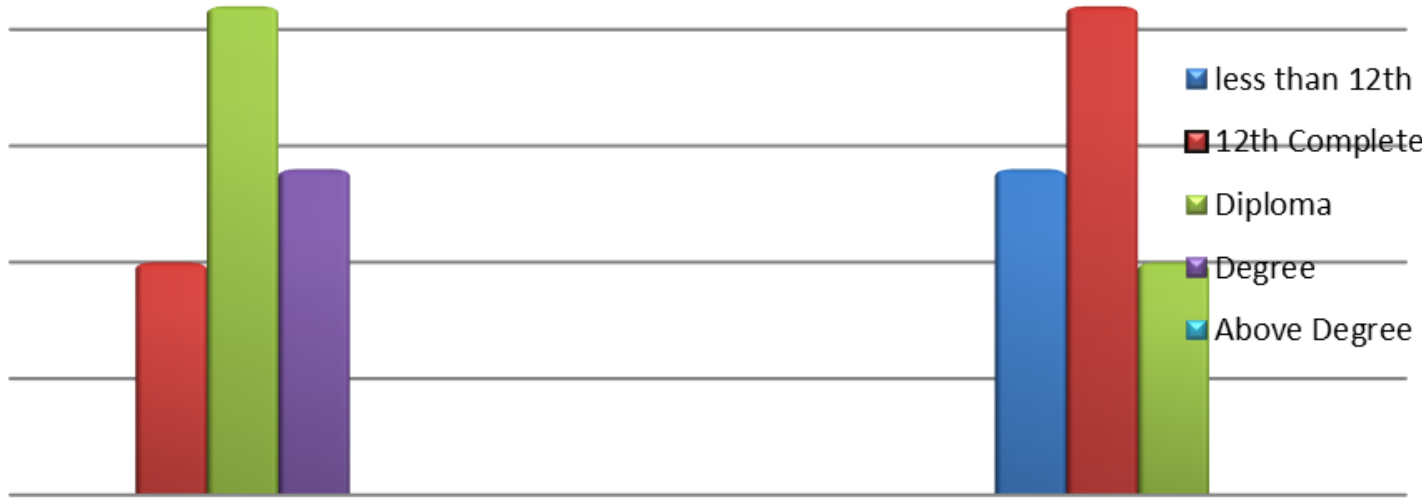

Source: Own Survey 2021,

Item 1, of the above table shows that out of the total respondents (45), 21 (46.67\%) of them were diploma holders, $14(31.11 \%)$ of the respondents were degree holders and the remaining $10(22.22 \%)$ of the respondents were 12 completed. This implies that $35(77.77 \%)$ of the respondents were hold as a minimum of diploma. This may good educational status to resolve conflict.

Item 2 of the above table indicates that 21(46.67\%) of the respondents had between 5-10 years of work experience, 14(31.11\%) of the respondents had less than 5 years experience of work and the remaining $10(22.22 \%)$ of them had between 16-30 years work experience. From this we can generalize that most of employees $31(68.89 \%)$ had at least 5 years experience. As a result they can resolve conflict by effective communication for the reason that they may know the working environment of their organization. But the remaining $46.67 \%$ had there own impact on not resolution of conflict.

\subsection{General Information}

This includes information gathered from employees of kebri Dehar municipality regarding the basic questions of the study.

\subsubsection{Conflict conditions and reasons for conflict}

Conflict occurs because people do not always agree on goals, issues, perception and so on. And also, conflict is pervasive in organizations. To manage it effectively, managers should understand the many source of conflict (Debral; 1994:392)

Table 2: Conflict conditions and reasons behind conflict.

\begin{tabular}{|l|l|l|l|}
\hline No & Item & \multicolumn{2}{|c|}{ Respondents } \\
\hline \multirow{4}{*}{1} & Existence of conflicts with in organization & No & \% (percent) \\
\cline { 2 - 4 } & Yes & 31 & 68.89 \\
\cline { 2 - 4 } & No & 14 & 31.11 \\
\cline { 2 - 4 } & Total & $\mathbf{4 5}$ & $\mathbf{1 0 0}$ \\
\hline \multirow{4}{*}{2} & Reasons for conflicts & No & \% (percent) \\
\cline { 2 - 4 } & Work over load & 11 & 35.48 \\
\cline { 2 - 4 } & Lack of information & 6 & 19.35 \\
\cline { 2 - 4 } & Communication gap to resolve conflict & 11 & 35.48 \\
\cline { 2 - 5 } & Any other & 3 & 9.67 \\
\cline { 2 - 4 } & Total & $\mathbf{3 1}$ & $\mathbf{1 0 0}$ \\
\hline
\end{tabular}

Source: Own Survey 2021,

Regarding the information in the above table of item one $31(68.89 \%)$ of the respondents replied that they faced conflict with the employees of their or/and other department. In addition, the remaining 14 (31.11\%) of the respondents responded that they did not face any conflict. This shows that the largest part of employees face conflict. The above information indicates that there were a conflict with in organization.

As item 2, of the above table shows $11(35.48 \%)$ of the respondents responded the reasons why they were conflicting was due to work over load form their superiors, similarly, 11(35.48\%) of the respondents replied that they faced conflict because of communication gap in resolving conflict and 6(19.35\%) of respondents responded lack of information was the main reason for conflict. There was also another reason for the conflict given by 
respondent such as responsibility of one or more persons for the same job, lack or awareness about his or her responsibility. This indicates that even if there were a various source of conflict, work over load and communication gap to resolve conflict were the major reasons for conflict among employees of the organization. In addition to employee's response, the information from manager by interview shows that the management faces different conflicts from the employees. These are on the question of salary increment and decreasing work over load, dual responsibility given by management, timeliness of important materials for the activities delegated and so on.

\subsubsection{Conditions of conflict avoidance and resolution techniques of conflict .}

To avoid dysfunctional conflict and stimulated functional conflict, management is advice to have conflict management skills and they can use stimulation and resolution technique

Table 3: Condition of conflict avoidance and techniques of conflict avoidance.

\begin{tabular}{|c|c|c|c|}
\hline No & Item & \multicolumn{2}{|c|}{ Respondents } \\
\hline \multirow{4}{*}{1} & Employee's attitude towards the avoidance of conflict situation & No & $\%$ (percent) \\
\hline & Yes & 43 & 95.56 \\
\hline & No & 2 & 4.44 \\
\hline & Total & 45 & 100 \\
\hline \multirow[t]{8}{*}{2} & Employees attitude on techniques used to resolve conflict & No & \%(Percent) \\
\hline & Discussions & 31 & 72.09 \\
\hline & Arbitration & 3 & 6.98 \\
\hline & Punishment & 5 & 11.63 \\
\hline & Court judgment & 1 & 2.33 \\
\hline & Compromise & 3 & 6.98 \\
\hline & Other & 0 & 0 \\
\hline & Total & 43 & 100 \\
\hline
\end{tabular}

Source: Own Survey 2021,

According to the information observed on the above table, item one, $43(95.56 \%)$ of the respondents believed that conflict occurring between or among employees in an organization were avoided and $2(4.44 \%)$ of the respondents were believed that the conflict could not avoided. This implies that nearly all employees think on the avoidance of conflict with in their organization. There fore the manager may not face obstacle to wards employees attitude on conflict resolution through effective communication.

Item 2, of the above table, shows that $31(72.09 \%)$ of the respondents believed the conflict can avoid through discussion, $5(11.63 \%)$ of the respondents responded that conflict can be avoided through punishing the conflicting parties, on other hand $3(6.98 \%)$ of the respondents replied that conflict can avoid through arbitration, similarly $3(6.98 \%)$ of the respondents responded that they can avoid conflict that occur between employees by putting the conflicting parties to hemiddle point, this is also called compromising the two parties and the remaining $1(2.33 \%)$ of the respondents responded that the conflict is avoided by going to court. This shows that the employees of municipality gave more value to discussion for resolving conflict.

In addition to the above response of employees, the manager answer shows that management tried to solve the conflicts that occur among employees as it can possible peace fully. It was based on the rules and regulations of the government. This implies that even if the management thinks that conflict between employees' decreases or reduces the over all service given by the organization, the emphasis they gave to communication in resolving conflict is very little.

\subsubsection{Conditions of discussion about the conflict situation}

Discussion is appears after communication. Effective communication can lead to resolve conflict 
Table 4: Conditions of discussion about the conflict situation

\begin{tabular}{|c|c|c|c|}
\hline No & Item & \multicolumn{2}{|c|}{ Respondents } \\
\hline \multirow[t]{4}{*}{1} & Existence of discussion concerning conflict & No & $\%$ (percent) \\
\hline & Yes & 13 & 28.89 \\
\hline & No & 32 & 71.11 \\
\hline & Total & 45 & 100 \\
\hline \multirow[t]{6}{*}{2} & Time interval of discussion with in organization concerning conflict & No & $\%$ (percent) \\
\hline & Once a month & 8 & 61.54 \\
\hline & Twice a month & 3 & 23.08 \\
\hline & Once a year & 2 & 15.38 \\
\hline & Other & 0 & 0 \\
\hline & Total & 13 & 100 \\
\hline \multirow[t]{6}{*}{3} & Reason for non-existence of discussion on conflict resolution & No & $\%$ (percent) \\
\hline & Because it is almost useless & 7 & 21.88 \\
\hline & Because there is no enough time & 6 & 18.75 \\
\hline & Because he management do not give attention or emphasis & 19 & 59.38 \\
\hline & Others & 0 & 0 \\
\hline & Total & 32 & 100 \\
\hline
\end{tabular}

Source: Own Survey 2021,

As indicated in the above table, item one, from the total 45 respondents, $32(71.11 \%)$ of the respondents responded that there was no any discussion concerning the conflict that occurs in their organization and the remaining $13(28.89 \%)$ of the respondents replied that there was discussion particulates to conflict resolution. The information shows that although there was a little discussion in organization, most of employees agreed on non-existence of discussion concerning conflict with in organization. This shows that the management and employees do not gave enough attention on discussion about conflict situation. Regarding the information in the above table item $2,8(61.54 \%)$ of the respondents responded that there was discussion about conflict once in amonth,3(23.08\%) of the respondents replied that there was discussion twice a month and the remaining $2(15.38 \%)$ of the respondents responded that there was discussion about conflict conditions once in a year. This shows that from the respondents who agreed on the existence of discussion, discussion were at least once in month in the municipality.

Item 3 of table 4 indicates that $19(59.38 \%)$ of the respondents replied there was no discussion regarding conflict because of the management's less attention, $7(21.88 \%)$ of the respondents responded that the reason for no conflict discussion was that it had no any use and no contribution to the organization. And the remaining $6(18.75 \%)$ of the respondent responded that they had no enough time to deal with such things. This shows that the management were not giving enough attention to the consequence of conflict to the organizational effectiveness.

\subsubsection{Managers and employees relationship conditions}

Management can have communication with subordinates on the purpose to assign goals, provide job instructions inform underlining feedback about performance. This type of relationship between managers and employee is down ward communication on the other hand subordinate can communicate with their managers to provide feedback, to prepare performance reports etc and this type of communication between two parties is called upward communication .

Table 5: Managers and employees relationship conditions

\begin{tabular}{|l|l|l|l|}
\hline No & Item & \multicolumn{2}{|c|}{ Respondents } \\
\hline \multirow{1}{*}{1} & Response of management to employees' grievances or complaints & No & \% (percent) \\
\cline { 2 - 4 } & High & 10 & 22.22 \\
\cline { 2 - 4 } & Medium & 16 & 35.56 \\
\cline { 2 - 4 } & Low & 19 & 42.22 \\
\cline { 2 - 4 } & Total & $\mathbf{4 5}$ & $\mathbf{1 0 0}$ \\
\hline
\end{tabular}

Source: Own Survey 2021,

Information regarding the above table indicates that $19(42.22 \%)$ of the respondents replied that grievances of employees was answered slowly or such service is low from the management, $16(35.56 \%)$ of respondents responded that the condition of employees grievances was answered in medium level and the remaining $10(22.22 \%)$ of the respondents stated that management highly response the employees complaint. This indicates that even if there were some level of a management response for employees' grievances or complaint, the majority $(77.78 \%)$ of employees answer shows there were a problem on the response of management.

From the result of interview with top manager of municipality, communication between the management and employees is relatively medium. The management communicate with employees at different issues such 
issues as to introduce and communicate on a new government polices, to set annual budget of the municipality and its workers, to appoint employees some specific jobs, and communicate when some employees give their compliment for the management. So that the researcher can conclude from mass of employees and the manager of the municipality that there was a problem on the response of management.

\subsubsection{Conditions of communication in the organization}

Communication in an organization Is the process of transmitting decisions and other information from one member or one part of an organization to other. In fact, there can be no organization with out communication (Stephen .P. Robbins; 1994:242).

Table 6: Conditions of communication in the organization

\begin{tabular}{|c|c|c|c|}
\hline $\mathbf{0}$ & Item & \multicolumn{2}{|r|}{ Respondents } \\
\hline \multirow[t]{4}{*}{1} & $\begin{array}{l}\text { Employee's attitude towards the role of communication to resolve } \\
\text { conflict with in their organization }\end{array}$ & No & $\%$ (percent) \\
\hline & Yes & 41 & 91.11 \\
\hline & No & 4 & 8.89 \\
\hline & Total & 45 & 100 \\
\hline & Function of communication with in organization & No & $\%$ (percent) \\
\hline & Sufficient & 29 & 64.44 \\
\hline & Not sufficient & 16 & 35.56 \\
\hline & Total & 45 & 100 \\
\hline & $\begin{array}{l}\text { The reason for not sufficient function of communication with in } \\
\text { organization }\end{array}$ & No & $\%$ (percent) \\
\hline & Lack of attention & 9 & 56.25 \\
\hline & Difference in attitude for communication & 2 & 12.5 \\
\hline & Lack of awareness regarding communication use & 5 & 31.25 \\
\hline & Other & 0 & 0 \\
\hline & Total & 16 & 100 \\
\hline & The level communication of role in resolving conflict in the company & No & $\%$ (percent) \\
\hline & High & 8 & 27.59 \\
\hline & Medium & 13 & 44.83 \\
\hline & Low & 8 & 27.59 \\
\hline & Total & 29 & 100 \\
\hline
\end{tabular}

Source: Own survey, 2021

Item 1 of table above, shows that $41(91.11 \%)$ of the respondents responded that they think communication plays a role in resolving conflict that occurred between employees in an organization and the remaining 4(8.89\%) of the respondents replied that communication does not play any role in conflict resolution process. Therefore, this implies that nearly all employees believe communication role in resolving conflict is a good awareness by employees of the company regarding communication use in resolving conflict in the municipality.

As indicated information above of table 6, item 2 shows that, $29(64.44 \%)$ of the respondents responded that communication in their organization was sufficient and the remaining $16(35.25 \%)$ of the respondent responded that the communication process in their organization was not sufficient. This shows that there is relatively sufficient communication as the majority respondents answered.

Item 3 , of table above shows that $9(56.25 \%$ ) of the respondents replied that the reason behind poor (not sufficient) communication between employees was lack of attention from management and employees, $5(31.25 \%)$ of the respondents responded that the reasons regarding not sufficient communication among employees was lack of awareness about its use and the remaining 2(12.5\%) of the respondents replied that because of the attitudinal differences of employees on the communication. Therefore, we can generalize from this there were various reasons behind poor communication of employees of Kebri Dehar municipality and from those reasons lack of attention and lack of awareness regarding communication use were the major for not sufficient communication of employees in Kebri Dehar manucipality.

According to Item 4 of table $6,13(44.83 \%$ ) of the respondents responded that the role of communication in resolving conflict is medium. Comparatively, $8(27.59 \%)$ of the respondents responded that the role of communication on resolving conflict was low and the remaining $8(27.59 \%)$ of the respondent responded that communication had high role in resolving conflict. From this, we can conclude that, even if there were relatively sufficient communication in organization, the role of communication in resolving conflict was not as such high regarding the majority $(72.42 \%)$ of respondent response.

3.3.6. Communication role and its constraints

Success in organization is dependent to a great degree up on the ability of the manager to understand other 
people. Managers can understand their employees through proper communication (Endalachew, Yasichelal and Tadiwos; 2006:66). Almost all conflicts involve communication problems, as both a cause and an effect. Misunderstanding, resulting from poor communication can easily cause a conflict or make it worse (Stewart and Sylvia; 2006:212)

Table 7: Communication role and its constraints

\begin{tabular}{|c|c|c|c|}
\hline \multirow[t]{2}{*}{ No } & \multirow[t]{2}{*}{ Items } & \multicolumn{2}{|c|}{ Respondents } \\
\hline & & No & $\%$ (percent) \\
\hline \multirow[t]{5}{*}{1} & Employee's relation ship in their day today activities of organization & & \\
\hline & Superiors & 22 & 48.89 \\
\hline & Co- workers & 14 & 31.11 \\
\hline & Subordinates & 9 & 20 \\
\hline & Total & 45 & 100 \\
\hline \multirow[t]{7}{*}{2} & Employees give more value towards communication role for:- & No & $\%$ (percent) \\
\hline & Resolving conflicts & 8 & 17.78 \\
\hline & Giving command & 2 & 4.44 \\
\hline & Discussion & 6 & 13.33 \\
\hline & Accomplishment of ordered work & 29 & 64.44 \\
\hline & Others & 0 & 0 \\
\hline & Total & 45 & 100 \\
\hline \multirow[t]{7}{*}{3} & Factors that affect communication not to achieve its goal & No & $\%$ (percent) \\
\hline & Cultural difference & 3 & 6.67 \\
\hline & Language difference & 2 & 4.44 \\
\hline & Aggressiveness( emotionality) & 8 & 17.78 \\
\hline & Difference in attitude towards communication & 30 & 66.67 \\
\hline & Others & 2 & 4.44 \\
\hline & Total & 45 & 100 \\
\hline
\end{tabular}

Source: Own survey, 2021

As shown in the above table item1, 22 (48.89\%) of the respondents responded that they have high relationship with their supervisors, $14(31.11 \%)$ of the respondents replied that they had high relationship with their co- workers and the remaining $9(20 \%)$ of the respondents responded that their relationship was with their subordinates. This shows that almost half of employees were highly interact with there superiors in their day-today activity. There fore they may face conflict with their superiors.

From the information, item 2 of the above table, 29(64.44\%) of respondents responded that they were gave more value for accomplishing ordered work, $8(17.78 \%)$ of the respondents responded that they were gave more value to communication roles of resolving conflict, $6(13.33 \%)$ of the respondent replied that they were gave more value to communication for discussing and the remaining $2(4.44 \%)$ of the respondents responded that they were gave more value for communication to give command or order. This implies that followed by their primarily activity of accomplish order work; the respondents respond more on resolving conflict. Therefore, conflict were a problem for the organization.

Item 3, of above table shows that $30(66.67 \%)$ of the respondents responded that attitude difference on communication is the most constraint for communication not to achieve its objectives, $8(17.78 \%)$ of the respondents replied that aggressiveness was among the constraints to communication $3(6.67 \%)$ of the respondents replied that cultural difference was a constraint to communication and the remaining $2(4.44 \%)$ of respondents responded that language difference was the greatest constraint to communication. In addition, $2(4.44 \%)$ of respondents responded that the shortage employees and the multiple of one employee is a constraint for not to achieve communication goal (resolving conflict). This indicates that even if there were various constraints of communication to achieve its goal (resolving conflict); the majority employees put attitudinal difference to wards communication as a major constraint.

\section{CONCLUSION AND RECOMMENDATION}

\subsection{Conclusion}

Based on the analysis of the workers of municipality conflict condition, communication and application of communication with conflict, the following important conclusion can be drawn.

* The largest part of employees faces conflict with other employees of their organization with the major reasons of work over load and communication gap to resolve conflict. This implies that there were conflict and the sources of conflict were from structural factors.

* Employees think on the avoidance of conflict with in their organization and they gave more value for discussion from the resolution technique of communication. There fore, If the manager communicates 
employees effectively, he may not face obstacle/problem towards employees' attitude on conflict resolution.

* Majority employees agree on non-existence of discussion and they put a major reason for this was management less attention. This indicates that the management was not give attention for the consequence of conflict to the organizational effectiveness.

* Less response of manager to employees grievances or complaint had a problem as a majority of respondent response and also from manager answer by interview. Therefore, we can say that management was not given enough value on employees' grievances or complaint.

* Majority of employees believed that communication plays role in resolving conflict. This shows that there was a good awareness of

* employees regarding communication use in resolving conflict in the municipality.

* As the response of majority respondents, communication in their organization was sufficient.

* As shown in the study, almost half of employees were highly interact with their supervisors in their day-to-day activity; therefore, they may face conflict with their superiors.

* Employees gave more value for resolving conflict from conflict roles followed by their primarily activity, accomplish ordered work this shows that there were conflict in organization.

* Difference in attitude towards communication were the major factor that affect communication role to not achieve its goals(resolving conflict) this shows that there were pessimistic employees with in the municipality.

\subsection{Recommendations}

Communication is essential to the employees of a given organization. Especially for managers to coordinate the human and non human resources of an organization, they require ability to communicate effectively. To coordinate these human resources they should avoid conflict that occurs between employees or between them and employees. To avoid these problems communication is vital

Based on the findings obtained and the conclusion drawn, in addressing the problems identified the researcher forwarded the following recommendations as a possible solution to be considered by respected body.

* The majority of employees face conflict because of different factors that lead to a decline in communication process. So the manager is advised to manage it effectively.

* To manage conflict effectively Management should:-understand the source of conflict whether it is structural or personal factors and use conflict resolution technique such asCompromise,

* Arbitration and Punishment.

* Nearly all employees believed that conflict can be avoided through discussion and for this, communication plays role. There fore the management is advised to use the positive attitude of employees to communicate effectively on conflict resolution process that is important for positive change of organization.

* The less attention from management is the major reasons for non-existence of discussion that may leads to conflict. Therefore, the management is advised to give enough attention to discussion and make effective communication.

* The response of management for employees' grievances is not appropriate to solve conflict. As a result, management is advised to give enough attention for employees' criticism and accept employees' comments and criticism towards organizational activities by implementing effective communication since employees feel less satisfied and lose a sense of belongingness to their organization.

* Communication with in organization was sufficient. so the management is advised to encourage this sufficient communication in to more effective, that result to organizational productivity.

* Role of communication in resolving conflict was less in the municipality that may decline the quality of service. For that reasons management is advice to use effective communication, that is the corner stone of strong and healthy relation ship.

* Difference in attitude of employees to wards communication was the major factor that affect communication role not to achieve its goals (resolving conflict). Thus, the management advised to encourage the employees attitude on positive thinking of communication in conflict resolution by discussion.

\section{REFERENCES}

DerbalL.Nelson and James Capbell Quick,(1994),Organizational Behaviour,2 $2^{\text {nd }}$ edUSA,West publishing company.

Endalchacew Kassa,Yaschelal Shitaye and Tadiwose Neway,(2006),Genral business student text grade 12 
revised Edition, Ethiopia, Kuraz international publisher.

I.VonGinow, Mary Ann Young and Stephen L.MC.Shane,(1976), Organizational behaviour, $1^{\text {st }}$ ed, Canada, Canadiancataloguing Publisher.

Mary Cllinan,(1998), Business communication, $2^{\text {nd }}$ ed, Harcourt Brace college publisher.

Ronald.B.Adler,(1989), Business communication, $2^{\text {nd }}$ ed,USA, Ronald house Inc.

S.AnwareReshid and Maurice Archer,(1983),Organizational Behaviour, $2^{\text {nd }} e d$, Canadia,Canadian cataloguing publisher.

Stephen P.Robbines,(1996)Organizational Behavior, $7^{\text {th }}$ ed,USA, Prentice Hall Inc.

Stephen P.Robbines,(1994),Business communication, $3^{\text {rd }}$ ed, Business communication, Canada, Canadian catalougingPublisher.

Stewart and Sylivia,(2006),Communication with in organization, $4^{\text {th }}$ ed ,USA,prenticeHall

Tom D.Daniels and Barry K.Spiker,(1994)Perspective on Organizational behavior,WCB, Brown and Bench Mark Publishers. 